\title{
Oxygen mass transfer impact on citric acid production by Yarrowia lipolytica from crude glycerol
}

\author{
Patrícia Ferreira, Marlene Lopes, Manuel Mota, Isabel Belo* \\ CEB-Centre of Biological Engineering, University of Minho, Campus de Gualtar, 4710-057 Braga, Portugal
}

\section{A R T I C L E I N F O}

\section{Article history:}

Received 9 October 2015

Received in revised form 13 January 2016

Accepted 2 February 2016

Available online 4 February 2016

\section{Keywords:}

Yarrowia lipolytica

Citric acid

Crude glycerol

Oxygen volumetric mass transfer

coefficient

Dissolved oxygen concentration

\begin{abstract}
A B S T R A C T
Production of citric acid from crude glycerol from biodiesel industry, in batch cultures of Yarrowia lipolytica W29 was performed in a lab-scale stirred tank bioreactor in order to assess the effect of oxygen mass transfer rate in this bioprocess.

An empirical correlation was proposed to describe oxygen volumetric mass transfer coefficient $\left(k_{\mathrm{L}} a\right)$ as a function of operating conditions (stirring speed and specific air flow rate) and cellular density. $k_{\mathrm{L}} a$ increased according with a power function with specific power input and superficial gas velocity, and slightly decreased with cellular density.

The increase of initial $k_{\mathrm{L}} a$ from $7 \mathrm{~h}^{-1}$ to $55 \mathrm{~h}^{-1}$ led to 7.8 -fold increase of citric acid final concentration. Experiments were also performed at controlled dissolved oxygen (DO) and citric acid concentration increased with DO up to $60 \%$ of saturation. Thus, due to the simpler operation setting an optimal $k_{\mathrm{L}} a$ than at controlled DO, it can be concluded that $k_{\mathrm{L}} a$ is an adequate parameter for the optimization of citric acid production from crude glycerol by $Y$. lipolytica and to be considered in bioprocess scale-up. Our empirical correlation, considering the operating conditions and cellular density, will be a valid tool for this purpose.
\end{abstract} (c) 2016 Elsevier B.V. All rights reserved.

\section{Introduction}

Yarrowia lipolytica is one of the most extensively studied "nonconventional" yeast, and is capable of using a wide range of carbon sources, such as sugars, alcohols, organic acids and hydrophobic compounds, like lipids and hydrocarbons [1-4], and convert them into several value-added products, such as lactones, enzymes and organic acids [5-8]. Moreover, this species has been proved to be very efficient using carbon sources from agro-industrial wastes [9-11].

Citric acid is traditionally produced by Aspergillus niger from molasse, a by-product of sugar industry (cane and beet), although other agro-industrial wastes have been successfully studied as alternative low-cost carbon source, such as apple pomace [12], corn cobs [13], carob pod [14], kiwi fruit peel [15], pineapple waste [16], orange waste [17], banana extract [18] and jackfruit wastes [19]. The production of citric acid by Y. lipolytica from low-cost carbon sources has also been reported, namely from glucose hydrol [20], pineapple waste [21], olive mill wastewater [22], cooking oil [23] and crude glycerol [24].

\footnotetext{
* Corresponding author at: CEB-Centre of Biological Engineering, University of Minho, Campus de Gualtar, 4710-057 Braga, Portugal. Fax: +351 253678986.

E-mail address: ibelo@deb.uminho.pt (I. Belo).
}

Biodiesel, a renewable energy, is an important alternative to the fossil fuels and its production increased considerably in the past few years. One problem associated with biodiesel industry is still the production costs and the accumulation into the market of high quantities of crude glycerol [25]. The purification of biodieselderived crude glycerol is not economically viable for the biodiesel plants. Therefore, the development of high-value compounds production from crude glycerol is critically important for the long-term sustainability of biodiesel industries. Some authors have reported the use of crude glycerol in microbial processes for production of, for example, 1,3-propanediol [26], poly(3-hydroxybutyrate) (PHB) [27], erythritol, mannitol [28] and citric acid [24]. In fact, under specific growth conditions, crude glycerol can be used by Y. lipolytica to produce citric acid [29].

$Y$. lipolytica is strictly aerobic and some studies have already showed the effect of oxygen mass transfer rate on yeast metabolism and products formation. The raise of oxygen transfer from gas phase to the culture medium resulted in an increase of cellular growth [30], lipase production [31] and $\boldsymbol{\gamma}$-decalactone secretion [32].

Oxygen availability is a key parameter in Y. lipolytica cultivation, substrate uptake rate and citric acid accumulation [33]. Moreover, dissolved oxygen concentration in the medium could directly influence the amount and type of organic compounds produced by the yeast [34-37]. Workman et al. [33] demonstrated that in Y. lipolytica 


\begin{tabular}{|c|c|}
\hline \multicolumn{2}{|c|}{ Nomenclature } \\
\hline \multicolumn{2}{|c|}{ List of abbreviations } \\
\hline$a$ & Specific Interfacial area $\left(\mathrm{m}^{-1}\right)$ \\
\hline$c$ & Constant dependent on the impeller \\
\hline C & $\begin{array}{l}\text { Dissolved oxygen concentration in the liquid } \\
\left(\mathrm{mg} \mathrm{L}^{-1}\right)\end{array}$ \\
\hline$C_{i}$ & $\begin{array}{l}\text { Dissolved oxygen concentration in the beginning } \\
\left(\mathrm{mg} \mathrm{L}^{-1}\right)\end{array}$ \\
\hline$C_{0}$ & $\begin{array}{l}\text { Dissolved oxygen concentration when aeration is } \\
\text { restarted }\left(\mathrm{mg} \mathrm{L}^{-1}\right)\end{array}$ \\
\hline$C^{*}$ & Solubility of oxygen in the liquid $\left(\mathrm{mg} \mathrm{L}^{-1}\right)$ \\
\hline$D_{i}$ & Impeller diameter $(\mathrm{m})$ \\
\hline DO & Dissolved oxygen concentration \\
\hline & Volumetric gas flow rate $\left(\mathrm{m}^{3} \mathrm{~s}^{-1}\right)$ \\
\hline ICA/CA & Isocitric/citric acids ratio $\left(\mathrm{g} \mathrm{g}^{-1}\right)$ \\
\hline$k_{\mathrm{L}}$ & Liquid side mass transfer coefficient $\left(\mathrm{m}^{3} \mathrm{~s}^{-1}\right)$ \\
\hline $\mathrm{k}_{\mathrm{L}} a$ & Oxygen volumetric mass transfer coefficient $\left(\mathrm{h}^{-1}\right)$ \\
\hline$K_{T}$ & Constant dependent on the impeller \\
\hline$N$ & Stirring speed (rps) \\
\hline$N_{\mathrm{p}}$ & Power number \\
\hline OUR & Oxygen uptake rate $\left(\mathrm{mg} \mathrm{g}^{-1} \mathrm{~h}^{-1}\right)$ \\
\hline OTR & Oxygen mass transfer rate $\left(\mathrm{mg} \mathrm{L}^{-1} \mathrm{~h}^{-1}\right)$ \\
\hline$p_{g}$ & Power input to the aerated system (W) \\
\hline$P_{\max }$ & Maximum productivity $\left(\mathrm{g} \mathrm{L}^{-1} \mathrm{~h}^{-1}\right)$ \\
\hline$q_{\mathrm{S}}$ & Specific substrate consumption rate $\left(\mathrm{g} \mathrm{g}^{-1} \mathrm{~h}^{-1}\right)$ \\
\hline $\operatorname{Re}$ & Reynolds number \\
\hline rpm & Rotation per minute \\
\hline STR & Stirred tank reactor \\
\hline$t$ & Time $(h)$ \\
\hline$t_{0}$ & Time when aeration is restarted $(\mathrm{h})$ \\
\hline$V$ & Bioreactor working volume $\left(\mathrm{m}^{3}\right)$ \\
\hline$v$ & Liquid viscosity $\left(\mathrm{kg} \mathrm{m}^{-1} \mathrm{~s}^{-1}\right)$ \\
\hline$v_{\mathrm{s}}$ & Superficial gas velocity $\left(\mathrm{m} \mathrm{s}^{-1}\right)$ \\
\hline vvm & Volume of air per volume of medium per minute \\
\hline$X$ & Cellular concentration $\left(\mathrm{g} \mathrm{L}^{-1}\right)$ \\
\hline YPDA & Yeast extract, peptone, dextrose, agar medium \\
\hline$Y_{\mathrm{CA} / \mathrm{S}}$ & $\begin{array}{l}\text { Citric acid yield per substrate mass consumed } \\
\left(\mathrm{g} \mathrm{g}^{-1}\right)\end{array}$ \\
\hline$Y_{\mathrm{X} / \mathrm{S}}$ & Cell mass yield per substrate mass consumed $\left(\mathrm{g} \mathrm{g}^{-1}\right)$ \\
\hline \multicolumn{2}{|c|}{ Greek letters } \\
\hline$\alpha, \beta, \delta$ & Non-linear models parameters to be fitted \\
\hline$\rho$ & Liquid density $\left(\mathrm{kg} \mathrm{m}^{-3}\right)$ \\
\hline$\mu$ & Maximum specific growth rate $\left(\mathrm{h}^{-1}\right)$ \\
\hline$\tau$ & Probe response time (s) \\
\hline
\end{tabular}

cultures mannitol and arabitol were produced from glycerol when oxygen limitation occurred. Additionally, it was reported that the increase of dissolved oxygen in glycerol media led to an improvement of citric acid production and to a reduction of isocitric/citric acid ratio [36,37], but no reference of oxygen mass transfer rate was reported.

Oxygen is a key substrate in any aerobic bioprocess since it is an important nutrient for microbial growth, maintenance and metabolites production. Thus, a continuous supply of oxygen to the culture broth is needed due to its low solubility in aqueous medium [38]. It is very important to know and, if possible, to predict the oxygen mass transfer rate (OTR) and volumetric oxygen mass transfer coefficient $\left(k_{\mathrm{L}} a\right)$ for different operating conditions to ensure sufficient oxygen transfer from the gas phase to the culture medium. OTR can be affected by several factors, such as geometrical characteristics of the bioreactor, operating conditions, physical properties of gas and liquid phases and by the presence of cells [38,39]. OTR and $k_{\mathrm{L}} a$ can be related by:

$\mathrm{OTR}=k_{\mathrm{L}} a\left(C^{*}-C\right)$

where $k_{\mathrm{L}} a$ is the mathematical product of mass transfer coefficient $\left(k_{\mathrm{L}}\right)$ and specific interfacial area $(a), C^{*}$ is the solubility of oxygen and $C$ is the dissolved oxygen concentration in the liquid phase.

Although several works regarding the production of citric acid from crude glycerol have been published, data on oxygen volumetric mass transfer rate and dissolved oxygen concentration required to support the production in this medium is still limited. Moreover, there is a lack of correlations to predict $k_{\mathrm{L}} a$ in production medium and the effect of active cells on oxygen mass transfer. The correct prediction of $k_{\mathrm{L}} a$ is a crucial step to achieve an optimum design operation and scale-up of bioreactors. Thus, experimental values of $k_{\mathrm{L}} a$ were obtained in a lab-scale stirred tank bioreactor (STR), by varying the stirring speed and the specific air flow rate, and its effect on citric acid production was evaluated. Data fitting to an empirical correlation for the prediction of $k_{\mathrm{L}} a$ as a function of superficial gas velocity and specific power input of the aerated bioreactor, based on Eq. (2), was attempted with a correction in order to predict the effect of cells in $k_{\mathrm{L}} a$.

Finally, the behavior of yeast growth, substrate consumption and citric acid production under constant dissolved oxygen concentration in the medium were analyzed in order to find which intrinsic parameter of oxygenation is more important for citric acid production, initial $k_{\mathrm{L}} a$ or controlled dissolved oxygen (DO). Thus, several batch experiments were performed at $20 \%, 40 \%$ and $60 \%$ of dissolved oxygen saturation.

\section{Materials and methods}

\subsection{Strain and medium}

Y. lipolytica W29 (ATCC 20460) was maintained in YPDA medium (glucose $20 \mathrm{~g} \mathrm{~L}^{-1}$, peptone $20 \mathrm{~g} \mathrm{~L}^{-1}$, yeast extract $10 \mathrm{~g} \mathrm{~L}^{-1}$ and agar $\left.20 \mathrm{~g} \mathrm{~L}^{-1}\right)$ at $4{ }^{\circ} \mathrm{C}$ for a maximum of two weeks.

\subsection{Bioreactor assay}

Yeast cells were pre-grown for $18 \mathrm{~h}$ in $500 \mathrm{~mL}$ Erlenmeyer flask filled with $200 \mathrm{~mL}$ of pure glycerol $20 \mathrm{~g} \mathrm{~L}^{-1}$, peptone $20 \mathrm{~g} \mathrm{~L}^{-1}$ and yeast extract $10 \mathrm{~g} \mathrm{~L}^{-1}$ medium, at $27^{\circ} \mathrm{C}$ and at $200 \mathrm{rpm}$.

Cells were centrifuged and resuspended in the production medium composed by $\left(\mathrm{g} \mathrm{L}^{-1}\right)$ : crude glycerol 50 ; yeast extract 0.5 ; $\mathrm{MgSO}_{4} \cdot \mathrm{H}_{2} \mathrm{O} 1.5 ; \mathrm{KH}_{2} \mathrm{PO}_{4} 6 ; \mathrm{Na}_{2} \mathrm{HPO}_{4} 0.5 ; \mathrm{CaCl}_{2} 0.75 ; \mathrm{FeCl}_{3} \cdot 6 \mathrm{H}_{2} \mathrm{O}$ $0.75 ; \mathrm{ZnSO}_{4} \cdot 7 \mathrm{H}_{2} \mathrm{O} 0.1 ; \mathrm{MnSO}_{4} \cdot \mathrm{H}_{2} 00.3$. Crude glycerol was provided by Prio Energy-Prio Biocombustiveis, SA and has the following composition (w/w): $90.4 \%$ glycerol, $9 \%$ water, $4.9 \% \mathrm{NaCl}$ and less than $0.001 \%$ methanol and $0.5 \%$ of organic matter (non-glycerol).

Batch assays were carried out in a $3.7 \mathrm{~L}$ bioreactor (RALF PLUS SOLO, Bioengineering, Switzerland) with $31 \mathrm{~cm}$ height and $17 \mathrm{~cm}$ diameter, and with Rushton impeller, 6 -blade, $6 \mathrm{~cm}$ outside diameter. The medium $\mathrm{pH}$ was maintain at 5 by addition of potassium hydroxide (2M) or orthophosphoric acid 21\% (v/v), through Peripex peristaltic pumps (Bioengineering, Switzerland). Dissolved oxygen concentration was measured with a polarographic-membrane probe (InPro 6000, Mettler Toledo, USA) using the BioScadaLab software.

The bioreactor, filled with $1.7 \mathrm{~L}$ of production medium, was inoculated at an initial cell density of $0.5 \mathrm{~g} \mathrm{~L}^{-1} \mathrm{Y}$. lipolytica cells and the assays were performed at $27^{\circ} \mathrm{C}$.

In order to evaluate the effect of initial $k_{\mathrm{L}} a$ on citric acid production, several experiments were carried out varying the specific air flow rate from $1 \mathrm{vvm}$ to $3 \mathrm{vvm}$ and changing the stirring speed from $200 \mathrm{rpm}$ to $600 \mathrm{rpm}$. 
Additionally, several assays with constant dissolved oxygen (20\%, $40 \%$ and $60 \%$ ) were performed. The DO concentration in the culture medium was controlled by manipulating the stirring speed and specific air flow rate, through a cascade control mode. In the cascade mode, the stirring speed and specific air flow rate automatically varied between the values studied in $k_{\mathrm{L}} a$ modeling (200-600 rpm of stirring speed and $1-3 \mathrm{vvm}$ of specific air flow rate).

Each experiment was replicated twice to ensure the repeatability and the reproducibility of the results.

\section{3. $\mathrm{k}_{L}$ a calculation}

Numerous empirical correlations have been proposed to calculate $k_{\mathrm{L}} a$, depending on the bioreactor configuration [38]. For a stirred tank bioreactor (STR) the most common function is given by Eq. (2) [40]:

$k_{\mathrm{L}} a=\alpha\left(\frac{P_{\mathrm{g}}}{V}\right)^{\beta} v_{\mathrm{s}}^{\gamma}$

where $P_{\mathrm{g}}$ is the power input to the aerated system, $V$ is the working volume, $v_{\mathrm{s}}$ represents the superficial gas velocity and $\alpha, \beta$ and $\gamma$ are non-linear models parameters to be fitted.

In order to estimate the power input to the aerated system $\left(P_{\mathrm{g}}\right)$, the Reynolds number $(R e)$ is determined by Eq. (3) and the power number $\left(N_{\mathrm{p}}\right)$ by Eq. (4):

$\operatorname{Re}=\frac{D_{i}^{2} N \rho}{v}$

$N_{p}=\frac{P_{g}}{\rho N^{3} D_{i}^{5}}$

where $D_{i}$ represents the impeller diameter, $N$ the stirring speed, $\rho$ the liquid density and $v$ the liquid viscosity. As the amount of glycerol added to the medium was small $(73 \mathrm{~mL}$ of glycerol in $1700 \mathrm{~mL}$ of medium, it was diluted 23-fold) and no other component of the medium or product would affect the viscosity of the medium, it was assumed the viscosity of water. Since the cell density was low and the metabolites produced did not significantly altered the viscosity, in $k_{\mathrm{L}} a$ determination in the fermentation medium with cells it was also assumed the viscosity of water.

If the Reynolds number is between 19,070 and 38,141 the flow regime inside the system is considered turbulent and $N_{\mathrm{p}}$ is not a function of $\operatorname{Re}[41]$. Thus, $P_{\mathrm{g}}$ without aeration $\left(P_{\mathrm{g}}^{\prime}\right)$ can be calculated by Eq. (5):

$P_{\mathrm{g}}^{\prime}=K_{T} D_{i}^{5} N^{3} \rho$

where $K_{T}$ represents a constant dependent on the impeller.

Finally, $P_{\mathrm{g}}$ in the aeration system is determined by Eq. (6):

$P_{\mathrm{g}}=c\left(\frac{P_{\mathrm{g}}^{\prime} N D_{i}^{3}}{F_{\mathrm{g}}^{0.56}}\right)^{0.45}$

where $c$ represents a constant that depends on the impeller used and $F_{\mathrm{g}}$ is the volumetric gas flow rate.

\subsubsection{Static gassing-out technique}

For experimental $k_{\mathrm{L}} a$ determination in blank assays (without cells), the static gassing-out technique was used. This method allows evaluating the effect of operational parameters, such as stirring speed and specific air flow rate, in the oxygen transfer efficiency [42]. After a preliminary gassing-out with compressed nitrogen to remove the oxygen in the medium, the aeration was switched on at specific conditions of specific air flow rate and stirring speed until saturation.
The technique is based in the oxygen mass balance equation (Eq. (7)) which, in the absence of cells and in batch mode, is simplified to the equality between the time variation of the dissolved oxygen concentration $(d C / d t)$ and the oxygen transfer rate from the gas to the liquid.

$\frac{d C}{d t}=k_{L} a\left(C^{*}-C\right)$

Integrating this equation, the value of $k_{\mathrm{L}} a$ was obtained, which is equal to the symmetrical slope of the plot of $\ln \left(C^{*}-C\right) v$ s. time [43].

The probe response time $(\tau)$ was estimated according to [44], and a value of $7 \mathrm{~s}$ was obtained. $k_{\mathrm{L}} a$ values were corrected according to Eq. (8)

$\frac{1}{k_{\mathrm{L}} a^{\prime}}=\frac{1}{k_{\mathrm{L}} a}+\tau$

where $k_{\mathrm{L}} a^{\prime}$ is the oxygen volumetric mass transfer coefficient determined experimentally.

\subsubsection{Dynamic gassing-out technique}

During citric acid production by Y. lipolytica cells, $k_{\mathrm{L}} a$ was determined using the dynamic gassing-out technique. The method is based on following the dissolved oxygen concentration in cultivation medium during a short interruption of the aeration [45]. In the presence of active cells and in the absence of aeration, the respiratory activity of yeast cells leads to the removal of oxygen of the liquid medium.

The procedure involves two steps: one to stop aeration and another to restart aeration at the operating conditions. Thus, in the first step, monitoring the decrease of dissolved oxygen concentration will allow to determine the specific oxygen uptake rate (OUR):

$\frac{d C}{d t}=-$ OUR

Aeration is restarted before reaching the critical dissolved oxygen concentration value [44]. After the resumption of aeration, the oxygen mass balance in the liquid phase is expressed by Eq. (10):

$\frac{d C}{d t}=k_{\mathrm{L}} a\left(C^{*}-C\right)-$ OUR

\section{4. $\mathrm{k}_{L}$ a modeling}

To take into account the effect of cellular concentration, $X$, on $k_{\mathrm{L}} a$, a correction of Eq. 2 was made (Eq. 11).

$k_{\mathrm{L}} a=\alpha\left(\frac{P_{\mathrm{g}}}{V}\right)^{\beta} v_{\mathrm{s}}^{\gamma}(1+X)^{\delta}$

The power input to the aerated system $\left(P_{\mathrm{g}}\right)$ and the superficial gas velocity $\left(v_{\mathrm{s}}\right)$ were calculated using the equations presented in the Section 2, converting the specific air flow rate to real volumetric gas flow rate $\left(F_{\mathrm{g}}\right)$. According to Michel and Miller [46], the parameters of these empirical equations depend of system geometry and are only valid for superficial gas velocity between $0.042 \mathrm{~m} \mathrm{~s}^{-1}$ and $0.180 \mathrm{~m} \mathrm{~s}^{-1}$ and stirring speed between $180 \mathrm{rpm}$ and $960 \mathrm{rpm}$, that cover the conditions used in this work.

For $k_{\mathrm{L}} a$ modeling, the data fitting to Eq. (11) was performed by least-squares non-linear regression using the Solver tool of Microsoft Excel 2010 software.

\subsection{Analytical methods}

Samples were collected at appropriate intervals for measurement of cell, glycerol and citric acid concentration. For quantification of cell concentration, optical density of cultures was 
measured at $600 \mathrm{~nm}$ and converted to dry cell mass per liter by a calibration curve. Glycerol concentration was quantified by highperformance liquid chromatography (HPLC) using a Metacarb $87 \mathrm{H}$ column $(300 \mathrm{~mm} \times 7.7 \mathrm{~mm})$ coupled to a RI detector. The eluent was $\mathrm{H}_{2} \mathrm{SO}_{4} 5 \mathrm{mM}$ at $0.5 \mathrm{~mL} \mathrm{~min}^{-1}$ and the column temperature was $60^{\circ} \mathrm{C}$, maintained with a column thermostat. Citric acid concentration was measured by HPLC using aYMC ODS-Aq $(250 \times 4.6 \mathrm{~mm})$ reverse phase column coupled to an UV detector at $214 \mathrm{~nm}$. The mobile phase was $\mathrm{KH}_{2} \mathrm{PO}_{4} 20 \mathrm{mM}$, pH 2.8 at room temperature and a flow rate of $0.7 \mathrm{~mL} \mathrm{~min}^{-1}$.

\section{Results and discussion}

\section{1. $\mathrm{k}_{L}$ a modeling in STR bioreactor}

To evaluate the effect of specific power input in the aerated system, the superficial gas velocity and cell density on $k_{\mathrm{L}} a$ values, several experiments were carried out in a 3.7-L stirred tank bioreactor, by changing simultaneously stirring speed and specific air flow rate. The experimental results of $k_{\mathrm{L}} a$ obtained in the different experimental conditions are presented in Table 1 . As expected for a STR bioreactor, the increment of stirring speed and specific air flow rate led to an enhancement of $k_{\mathrm{L}} a$ value. A 18 -fold improvement in $k_{\mathrm{L}} a$ values were obtained by increasing the specific air flow rate from $1 \mathrm{vvm}$ to $3 \mathrm{vvm}$ and the stirring speed from $200 \mathrm{rpm}$ to $600 \mathrm{rpm}$. The $k_{\mathrm{L}} a$ experimental value for the assay at $200 \mathrm{rpm}$ of stirring speed and $1 \mathrm{vvm}$ of specific air flow rate with cells was not possible to calculate, since a total depletion of oxygen through time of production process was recorded.

Table 1

Experimental $k_{\mathrm{L}} a$ values under different experimental conditions. Data are presented as the average and standard deviation of two independent experiments.

\begin{tabular}{lllll}
\hline \multicolumn{2}{l}{ Experimental conditions } & & & \multicolumn{2}{l}{$k_{\mathrm{L}} a\left(\mathrm{~h}^{-1}\right)$} \\
\cline { 1 - 2 } Specific air flow rate (vvm) & Stirring speed $(\mathrm{rpm})$ & & Without cells & With cells \\
\hline 1 & 200 & $7 \pm 0$ & $30 \pm 1$ & - \\
1.5 & 300 & $55 \pm 3$ & $18 \pm 2$ \\
2 & 500 & $84 \pm 3$ & $81 \pm 1$ \\
2.5 & 600 & $125 \pm 15$ & $89 \pm 3$ \\
3 & & &
\end{tabular}

Several parameters, from fluid properties to bioreactor geometry, can influence the $k_{\mathrm{L}} a$ estimation in the system. The determination of $k_{\mathrm{L}} a$ is a crucial step in bioreactor design, allowing to quantify the effect of the operating variables on the provision of oxygen and to establish the aeration capacity of the bioreactor system. Using the experimental data obtained in the assays with increased stirring speed and specific air flow rate (Table 1 ), in citric acid medium with and without yeast cells, the values of $\alpha, \beta, \gamma$ and $\delta$ parameters from Eq. (11) were estimated as indicated in Eq. (12):

$k_{\mathrm{L}} a=86\left(\frac{P_{\mathrm{g}}}{V}\right)^{0.51} v_{\mathrm{s}}^{0.46}(1+X)^{-0.12}$

For the empirical equation, $P_{\mathrm{g}} / V$ values ranged from $7.9 \mathrm{~W} \mathrm{~m}^{-3}$ to $191.0 \mathrm{~W} \mathrm{~m}^{-3}, v_{\mathrm{s}}$ from $2.3 \times 10^{-3} \mathrm{~m} \mathrm{~s}^{-1}$ to $6.9 \times 10^{-3} \mathrm{~m} \mathrm{~s}^{-1}$ and $X$ from $0 \mathrm{~g} \mathrm{~L}^{-1}$ to $6.23 \mathrm{~g} \mathrm{~L}^{-1}$. For aqueous systems, a wide range for the parameters values were proposed in the literature, in which exponent of $P_{\mathrm{g}} / V$ varied between 0.3 and 0.8 and exponent of $v_{\mathrm{s}}$ varied from 0.4 to $1[38,47]$. These variations resulted from differences in physicochemical properties (ionic strength, viscosity and surface tension) of the culture broths used by the authors. The results obtained in the present work, in a citric acid production medium, show that the $k_{\mathrm{L}} a$ dependence is slightly higher on the specific power input than on the superficial gas velocity, once the exponent of $v_{\mathrm{s}}$ is lower than the exponent of $\left(P_{\mathrm{g}} / V\right)$. In previous work
[32], in the same bioreactor but with a biphasic culture medium (oil-in-water emulsion), a same influence of the power input ( $\beta$ of 0.5 ) was obtained, but a lower influence of superficial gas velocity ( $\alpha$ of 0.2 ) was found.

The presence of cells in the system resulted in a slight negative effect on $k_{\mathrm{L}} a$. Also other authors reported a decrease in the $k_{\mathrm{L}} a$ values with the increase in cell concentration $[48,49]$. This effect may be explained by the effect of cells as solid particles that may block the transfer of oxygen from air bubbles to the liquid phase [38].

In Fig. 1, predicted $v s$. experimental $k_{\mathrm{L}} a$ results are represented with a line slope close to 1 , which indicates a good approximation between real $k_{\mathrm{L}} a$ values and the values calculated by the correlation.

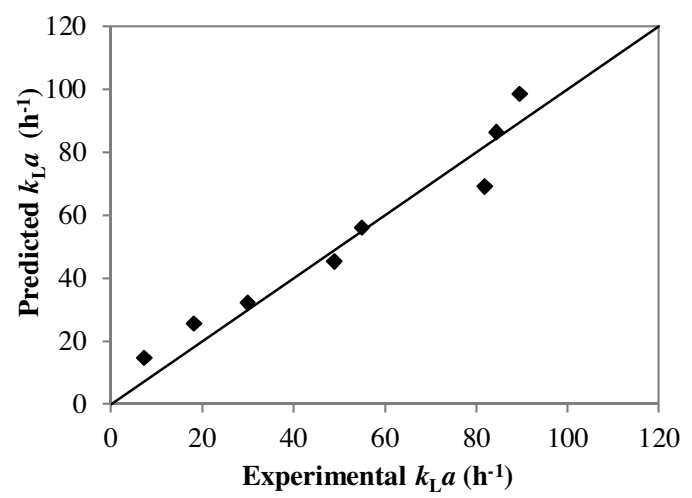

Fig. 1. Correlation between the experimental and predicted $k_{\mathrm{L}} a$ values using Eq. 12 .

\subsection{Effect of initial $\mathrm{k}_{L}$ a on citric acid production}

In order to evaluate the effect of initial $k_{\mathrm{L}} a$ on citric acid production, several experiments were performed varying simultaneously the stirring speed and specific air flow rate. The raise of initial $k_{\mathrm{L}} a$ from $7 \mathrm{~h}^{-1}$ to $125 \mathrm{~h}^{-1}$, due to an increase of specific air flow rate and stirring speed, had a positive impact on citric acid production (Fig. 2c). At lower initial $k_{\mathrm{L}} a$ value $\left(7 \mathrm{~h}^{-1}\right)$ the cells presented longer lag phase than in the higher values, and no significant differences were observed for cellular growth between them (Fig. 2a). Additionally, the crude glycerol consumption profile was similar for all the experiments, with exception for the assay at lower initial $k_{\mathrm{L}} a$ value (Fig. 2b).

As expected, according with initial $k_{\mathrm{L}} a$ conditions, different dissolved oxygen profiles were observed in batch cultures of $Y$. lipolytica (Fig. 3). During the first hours of yeast cultivation (corresponding to the exponential growth phase) a decrease on oxygen concentration in the medium was observed, particularly in the experiments with lower values of initial $k_{\mathrm{L}} a\left(7 \mathrm{~h}^{-1}\right.$ and $\left.30 \mathrm{~h}^{-1}\right)$. In fact, for an initial $k_{\mathrm{L}} a$ value of $7 \mathrm{~h}^{-1}$, a full depletion of oxygen from the medium was observed through all the process, which can justify the lower biomass and citric acid concentrations obtained in this condition. In the phase of citric acid production (after the nitrogen source had been completely consumed), the oxygen demand is lower and a raise of oxygen concentration in the medium has been reported $[36,50,51]$. In the experiments with an initial $k_{\mathrm{L}} a$ value equal to $30 \mathrm{~h}^{-1}$, the dissolved oxygen concentration dropped to zero in the first hours but stabilized around $20 \%$ during the citric acid production. For the other initial $k_{\mathrm{L}} a$ conditions, the oxygen concentration in the medium never fell to zero and stabilized around $55 \%, 70 \%$ and $85 \%$ for $k_{\mathrm{L}} a$ values of $55 \mathrm{~h}^{-1}, 84 \mathrm{~h}^{-1}$ and $125 \mathrm{~h}^{-1}$, respectively.

The raise of initial $k_{\mathrm{L}} a$ from $7 \mathrm{~h}^{-1}$ to $55 \mathrm{~h}^{-1}$ led to an increase of citric acid concentration and maximum productivity (Fig. 4). 

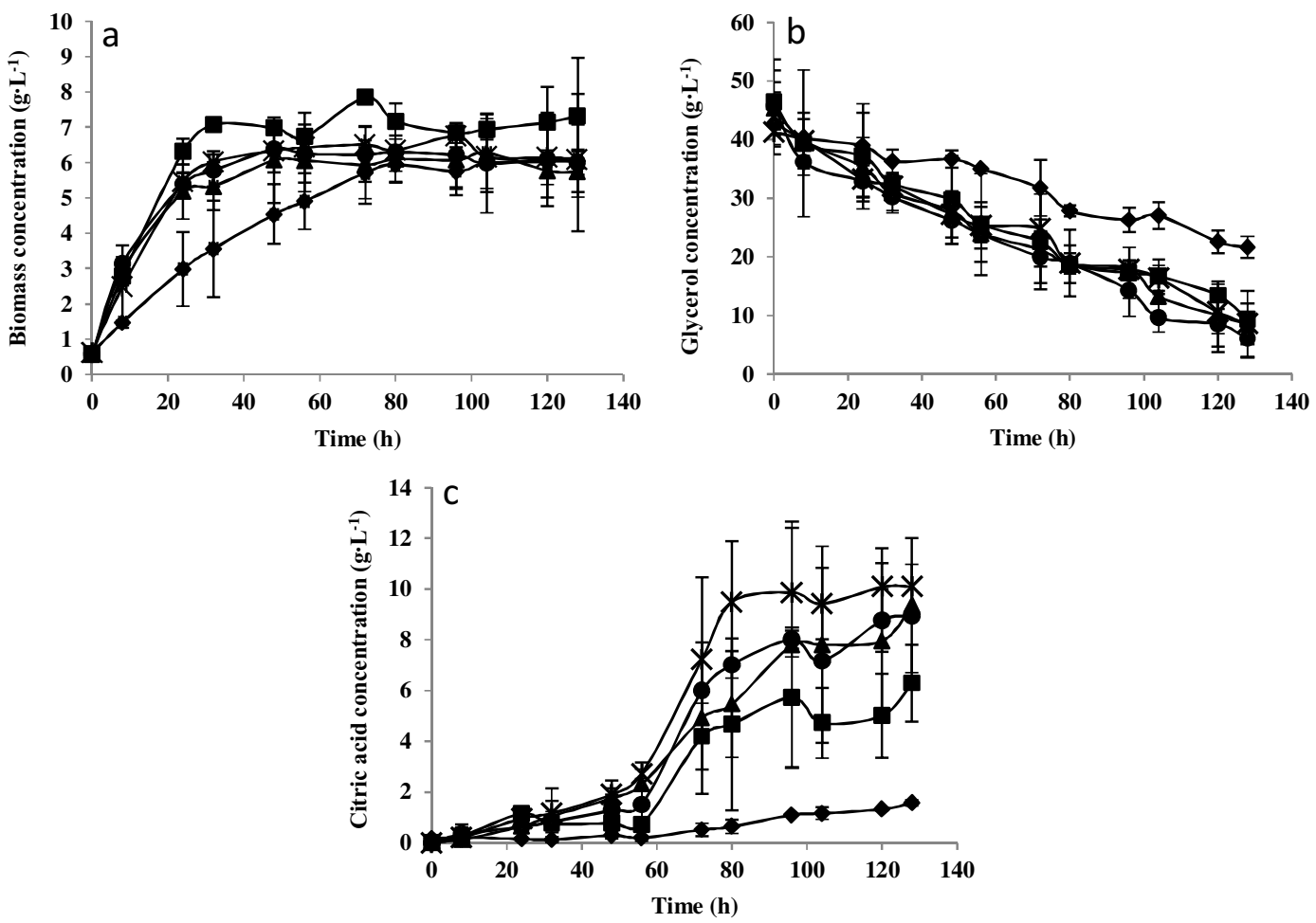

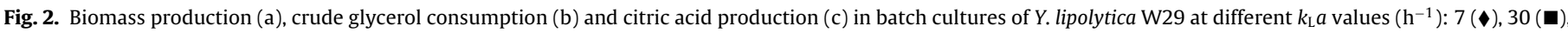
$55(\boldsymbol{\Lambda}), 84(\bullet)$ and $125(\times)$. The error bars represent the standard deviation of two independent replicates.

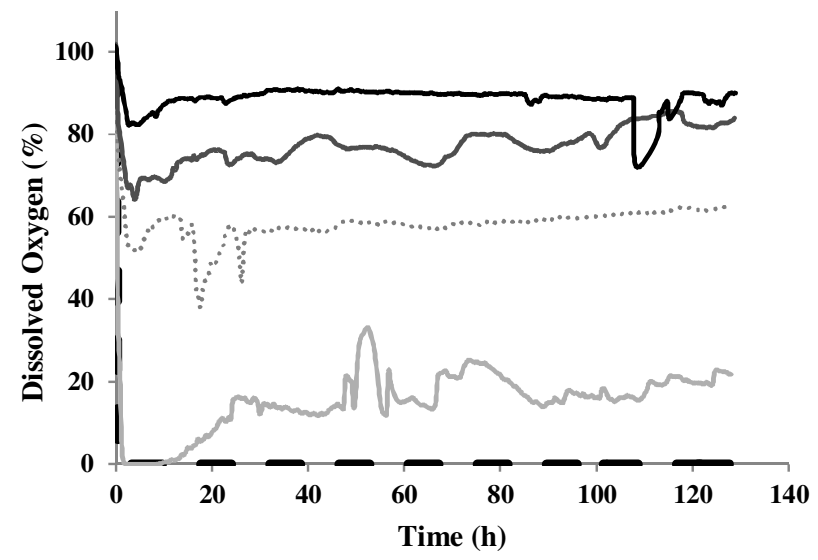

Fig. 3. Dissolved oxygen concentration profiles during citric acid production in batch cultures of $Y$. lipolytica W29 at different $k_{\mathrm{L}} a$ values $\left(\mathrm{h}^{-1}\right): 7$ (dashed line); 30 (light grey line); 55 (dotted line); 84 (dark grey line); 125 (black line).

Approximately 8-fold improvement in citric acid concentration and maximum productivity was observed. The lower concentration was attained in the experiments where a full oxygen depletion from the medium was observed and the highest citric acid concentration was reached in the experiments where the dissolved oxygen remained above $55 \%$.

Other authors have demonstrated the positive effect of increasing stirring speed from $400 \mathrm{rpm}$ to $800 \mathrm{rpm}$ [36] and to $1000 \mathrm{rpm}$ [2] on citric acid production, but did not calculate or estimate $k_{\mathrm{L}} a$.

The small amount of citric acid produced at lower initial $k_{\mathrm{L}} a$ value can be due to variations on the activity of important enzymes involved on citric acid production. Some authors observed a decrease in citric acid production under low aeration conditions, which was associated with a decrease in the activity of enzymes involved in tricarboxylic acid cycle and glyoxylate cycle [52,53].

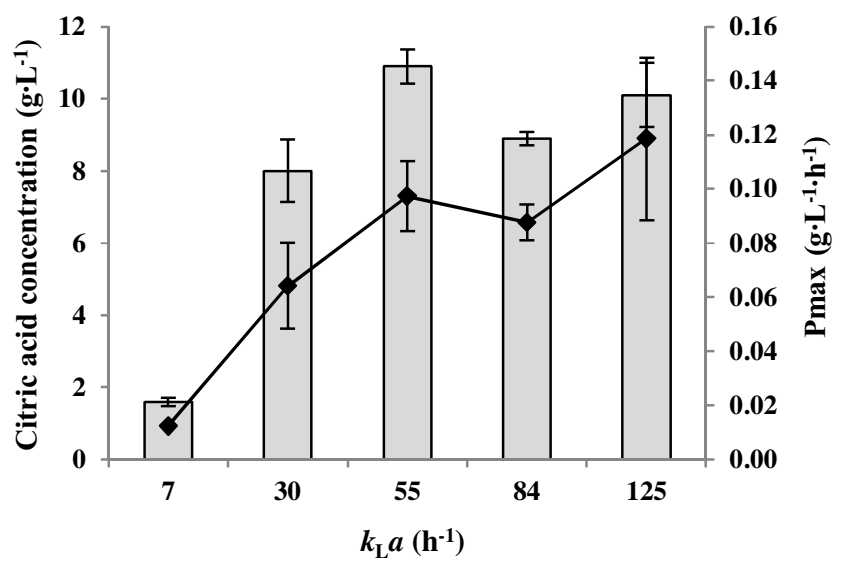

Fig. 4. Effect of $k_{\mathrm{L}} a$ on citric acid concentration (bars) and maximum productivity (dots). Citric acid productivity was calculated by the ratio between the maximum citric acid concentration obtained in each experiment and respective time. The error bars represent the standard deviation of two independent replicates.

At low aeration conditions, a reduced activity of citrate synthase, aconitate hydrate and NAD-dependent isocitrate dehydrogenase was observed. Additionally, an increase on the ATP-citrate lyase activity, responsible to the cleavage of citrate, was noticed. Moreover, the activity of isocitrate lyase and malate synthase, which are enzymes from glyoxylate cycle and are involved in the cleavage of isocitrate to succinate and malate, decreased under low oxygen concentration conditions. This pathway presents the major source of succinate and malate to mitochondria during intensive citric acid production. With the reduction of these enzymes activity from glyoxylate cycle, the increase of ATP-citrate lyase activity provides an alternative source for mitochondrial activity, not allowing an accumulation of citric acid [52]. 

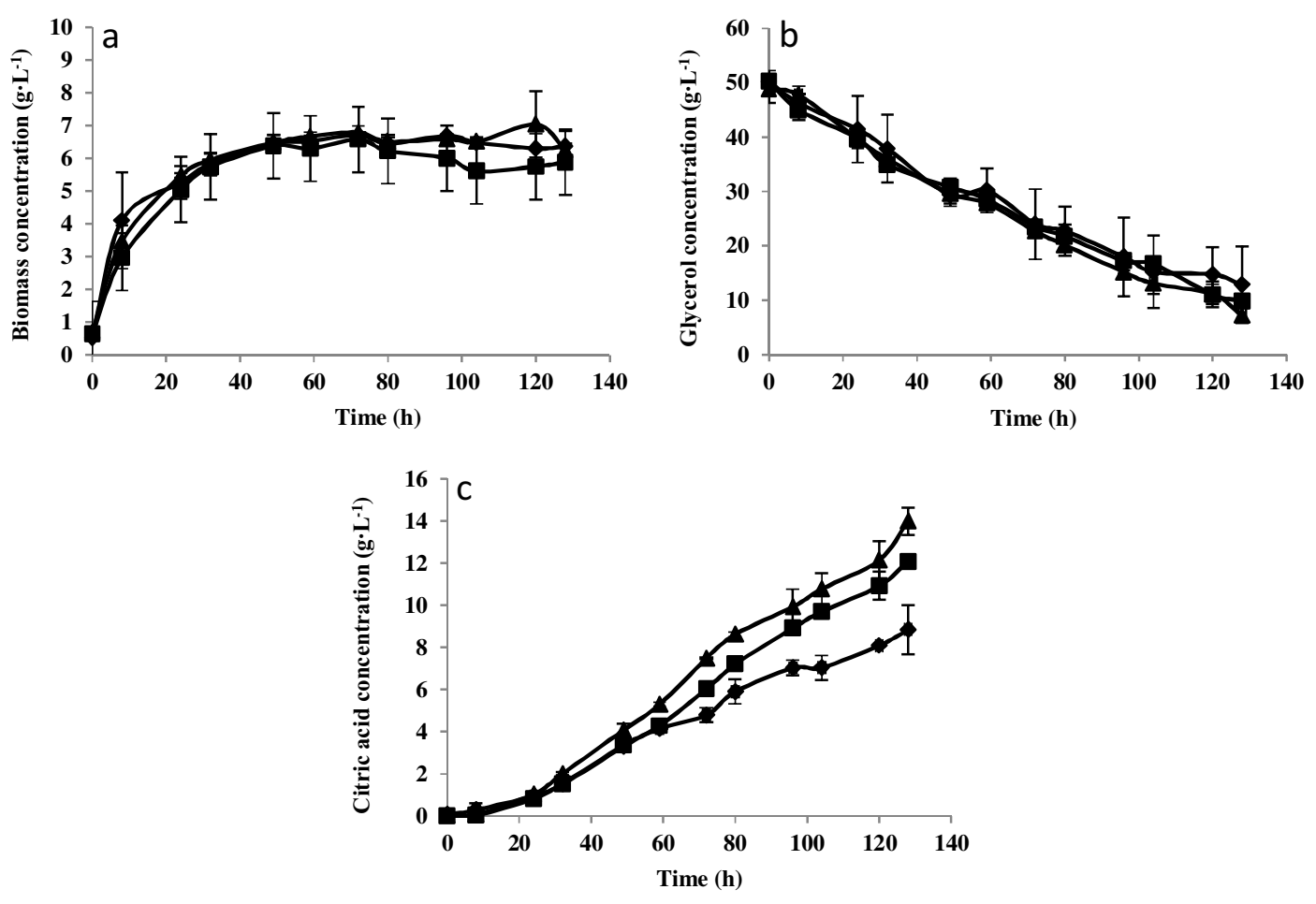

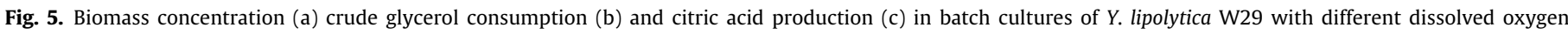
concentrations (\%): $20(\diamond), 40(\mathbf{\square}), 60(\boldsymbol{\Delta})$. The error bars represent the standard deviation of two independent replicates.

Above an initial $k_{\mathrm{L}} a$ of $55 \mathrm{~h}^{-1}$, no differences were observed in citric acid concentration and productivity. Probably, the highest stirring speed used in this study affected cell morphology and viability and, consequently, yeast metabolism. Changes in morphology of $Y$. lipolytica cells growing in similar range of stirring speed and specific air flow rate were reported by Braga et al. [32].

The increase of initial $k_{\mathrm{L}} a$ from $7 \mathrm{~h}^{-1}$ to $30 \mathrm{~h}^{-1}$ led to a $48 \%$ increase in specific growth rate (Table 2). At initial $k_{\mathrm{L}} a$ of $30 \mathrm{~h}^{-1}$, $55 \mathrm{~h}^{-1}, 84 \mathrm{~h}^{-1}$ and $125 \mathrm{~h}^{-1}$, no statistical differences in specific cellular growth rates were observed. Moreover, the highest biomass yield was attained with the lowest value of initial $k_{\mathrm{L}} a$. Also Crolla and Kennedy [2] demonstrated that increasing stirring speed from $400 \mathrm{rpm}$ to $900 \mathrm{rpm}$ (with constant specific air flow rate of $1 \mathrm{vvm}$ ) did not affect the Candida lipolytica cells concentration, but the lower stirring speed resulted in higher biomass yield. The highest specific glycerol consumption rate $\left(q_{\mathrm{s}}\right)$ and citric acid yield $\left(Y_{\mathrm{CA} / \mathrm{S}}\right)$ were obtained in the experiments performed with an initial $k_{\mathrm{L}} a$ equal to $55 \mathrm{~h}^{-1}$. A 2.7 -fold and 4.4-fold improvement in glycerol consumption rate and citric acid yield, respectively, was obtained increasing the initial $k_{\mathrm{L}} a$ from $7 \mathrm{~h}^{-1}$ to $55 \mathrm{~h}^{-1}$.

In addition to the influence on citric acid production, $k_{\mathrm{L}} a$ also affected the isocitric/citric acid (ICA/CA) ratio. A considerably decrease (2.1-fold) of this parameter was attained raising the initial $k_{\mathrm{L}} a$ from $7 \mathrm{~h}^{-1}$ to $125 \mathrm{~h}^{-1}$. Other studies described that isocitric acid percentage decreased with an increase of stirring speed or specific air flow rate [36]. This result is particularly important for the downstream process, diminishing the global cost of citric acid purification.

\subsection{Effect of controlled dissolved oxygen on citric acid production}

Dissolved oxygen concentration in the production medium is an operational parameter that can influence the bioprocess overall performance. The maintenance of an adequate oxygen concentration through all the time is a challenge and a crucial step to maximize microbial growth and metabolites production.
Considering the oxygen profiles obtained in the previous assays and discussed above, several experiments were performed with constant dissolved oxygen concentrations and the values of $20 \%$, $40 \%$ and $60 \%$ were chosen. These values of DO were controlled by manipulating the stirring speed and specific air flow rate, through a cascade control mode. The concentrations were selected taking into account the DO profiles obtained from the $k_{\mathrm{L}} a$ assays: (a) 60\% was, approximately, the value at which the dissolved oxygen stabilized in the initial $k_{\mathrm{L}} a$ condition with higher concentration of citric acid; (b) $20 \%$ was the lowest dissolved oxygen concentration (different of $0 \%$ ) obtained during citric acid production; and (c) $40 \%$ is an intermediate value.

Although Y. lipolytica is a strictly aerobic microorganism, no differences were found in the growth profiles and cell density reached with increased DO concentrations in the medium (Fig. 5a). Also, glycerol consumption had the same behavior for all conditions tested (Fig. 5b). In contrast, an enhancement of citric acid production was obtained with the raise of DO concentration (Fig. 5c). A 1.4and 1.6-fold improvement in citric acid concentration was attained by increasing the DO concentration in the medium from $20 \%$ to $40 \%$ and to $60 \%$, respectively (Fig. 6). Additionally, the maximum productivity was positively affected by the raise of DO concentration up to $60 \%$ and a 1.3 -fold improvement was obtained compared to the assays carried out with $20 \%$ DO.

Independently the DO concentration in the medium, no differences were observed in specific growth rate, biomass yield and glycerol specific consumption rate (Table 3). However, a 1.6-fold improvement in citric acid yield was attained in the experiments with $60 \%$ of DO compared to the assays carried out at $20 \%$.

These results are in accordance with previous works published by Kamzolova et al. [53] and Finogenova et al. [52], which reported the increase of citric acid production, in batch and continuous cultures of $Y$. lipolytica N1, when the DO concentration in the medium was equal to $60 \%$. However, Anastassiadis and Rehm [54] observed that the maximum citric acid production by Candida oleophila, in continuous mode, was achieved with a DO of $20 \%$. 
Table 2

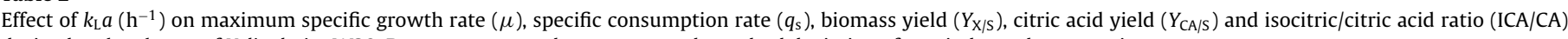
during batch cultures of $Y$. lipolytica W29. Data are presented as average and standard deviation of two independent experiments.

\begin{tabular}{|c|c|c|c|c|c|}
\hline & \multicolumn{5}{|l|}{$k_{\mathrm{L}} a\left(\mathrm{~h}^{-1}\right)$} \\
\hline & 7 & 30 & 55 & 84 & 125 \\
\hline$\mu\left(\mathrm{h}^{-1}\right)$ & $0.062 \pm 0.014$ & $0.092 \pm 0.004$ & $0.086 \pm 0.009$ & $0.085 \pm 0.005$ & $0.085 \pm 0.006$ \\
\hline$q_{\mathrm{s}}\left(\mathrm{g} \mathrm{L}^{-1} \mathrm{~h}^{-1}\right)$ & $0.24 \pm 0.05$ & $0.51 \pm 0.02$ & $0.65 \pm 0.24$ & $0.68 \pm 0.32$ & $0.61 \pm 0.15$ \\
\hline$Y_{\mathrm{X} / \mathrm{S}}\left(\mathrm{g} \mathrm{g}^{-1}\right)$ & $0.26 \pm 0.01$ & $0.18 \pm 0.01$ & $0.14 \pm 0.04$ & $0.14 \pm 0.08$ & $0.14 \pm 0.03$ \\
\hline$Y_{\mathrm{CA} / \mathrm{S}}\left(\mathrm{g} \mathrm{g}^{-1}\right)$ & $0.07 \pm 0.00$ & $0.17 \pm 0.01$ & $0.31 \pm 0.11$ & $0.23 \pm 0.04$ & $0.27 \pm 0.06$ \\
\hline ICA/CA $\left(\mathrm{g} \mathrm{g}^{-1}\right)$ & $0.21 \pm 0.02$ & $0.16 \pm 0.03$ & $0.14 \pm 0.05$ & $0.11 \pm 0.01$ & $0.10 \pm 0.05$ \\
\hline
\end{tabular}

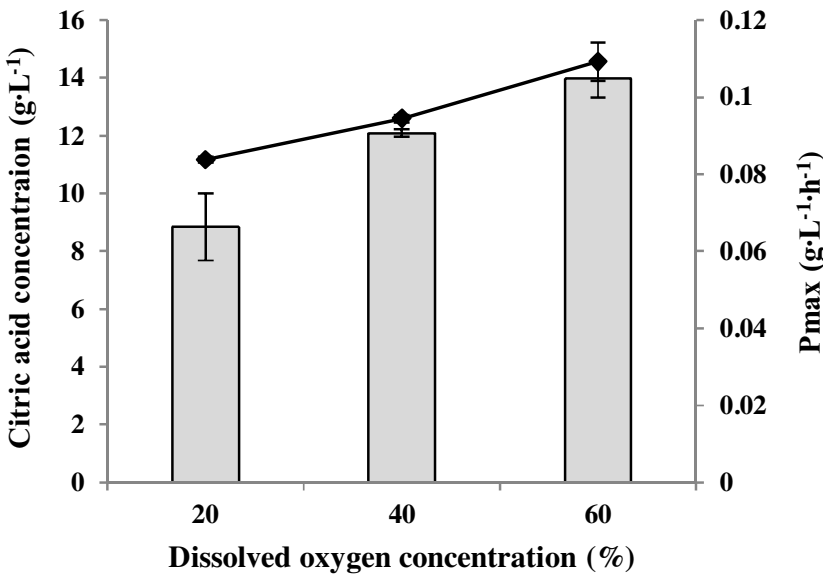

Fig. 6. Effect of dissolved oxygen (\%) on citric acid concentration (bars) and maximum productivity (dots). Citric acid productivity was calculated by the ratio between the maximum citric acid concentration obtained in each experiment and respective time. The error bars represent the standard deviation of two independent replicates.

Table 3

Effect of dissolved oxygen concentration (\%) on maximum specific growth rate $(\mu)$, specific consumption rate $\left(q_{\mathrm{s}}\right)$, biomass yield $\left(Y_{\mathrm{X} / \mathrm{S}}\right)$ and citric acid yield $\left(Y_{\mathrm{CA} / \mathrm{S}}\right)$ during bath culture of $Y$. lipolytica W29. Data are presented as average and standard deviation of two independent experiments.

\begin{tabular}{lccc}
\hline & \multicolumn{3}{l}{ Dissolved oxygen concentration (\%) } \\
\cline { 2 - 4 } & 20 & 40 & 60 \\
\hline$\mu\left(\mathrm{h}^{-1}\right)$ & $0.085 \pm 0.002$ & $0.079 \pm 0.006$ & $0.077 \pm 0.000$ \\
$Y_{\mathrm{X} / \mathrm{S}\left(\mathrm{g} \mathrm{g}^{-1}\right)}$ & $0.16 \pm 0.04$ & $0.13 \pm 0.01$ & $0.15 \pm 0.02$ \\
$q_{\mathrm{s}}\left(\mathrm{g} \mathrm{g}^{-1} \mathrm{~h}^{-1}\right)$ & $0.5 \pm 0.1$ & $0.6 \pm 0.1$ & $0.5 \pm 0.1$ \\
$Y_{\mathrm{CA} / \mathrm{S}}\left(\mathrm{g} \mathrm{g}^{-1}\right)$ & $0.235 \pm 0.006$ & $0.299 \pm 0.005$ & $0.37 \pm 0.04$ \\
\hline
\end{tabular}

Comparing the results obtained in the experiments carried out with initial $k_{\mathrm{L}} a$ and controlled dissolved oxygen, it was observed that citric acid concentrations obtained using controlled DO (20\% and $60 \%$ ) was similar to those attained in experiments with initial $k_{\mathrm{L}} a$ of $30 \mathrm{~h}^{-1}$ and $55 \mathrm{~h}^{-1}$, respectively.

Considering the small differences in citric acid production obtained in the two operational approaches discussed above, and from an industrial perspective, operating at constant values of stirring speed and aeration rate will be easier and less technologically demanding. Moreover, in this work, when DO was controlled at $20 \%$ and $60 \%$, the stirring speed needed to achieve these oxygen concentrations were higher than those used at initial $k_{\mathrm{L}} a$ of $30 \mathrm{~h}^{-1}$ and $55 \mathrm{~h}^{-1}$, respectively (data not shown), thus representing an increase of operating costs due to power consumption. For the reasons explained above, setting initial $k_{\mathrm{L}} a$ was proven to be an adequate strategy of optimization of the bioprocess of citric acid production from glycerol by Y. lipolytica W29.

\section{Conclusions}

Citric acid production by Y. lipolytica W29, from crude glycerol, was evaluated considering the effect of oxygen using two different strategies: constant stirring speed and aeration to give a determined initial $k_{\mathrm{L}} a$ and constant dissolved oxygen concentration.

An empirical correlation to predict $k_{\mathrm{L}} a$ value as a function of operating conditions (superficial gas velocity and specific power input), as well of cellular density was established.

The increase of initial $k_{\mathrm{L}} a$ resulted in an increase of citric acid production and a decrease of ICA/CA ratio. The maximum citric acid concentration was achieved with an intermediate value of initial $k_{\mathrm{L}} a\left(55 \mathrm{~h}^{-1}\right)$. The raise of dissolved oxygen concentration led to an increase of citric acid yield and productivity, achieved either by controlling dissolved oxygen concentration at constant values or by increasing stirring speed and specific air flow rate to give adequate initial $k_{\mathrm{L}} a$ values. This last strategy appears to be a more economically attractive approach, from an industrial implementation perspective.

This work demonstrated the importance of $k_{\mathrm{L}} a$ in citric acid production by $Y$. lipolytica from crude glycerol and the correlation proposed will be very useful for further work on the development of strategies for the optimization and scale-up of this bioprocess.

\section{Acknowledgments}

This work was financially supported by Portuguese Foundation for Science Technology and the European Community fund FEDER through Program COMPETE under $\mathrm{PhD}$ grant SFRH/BD/72621/2010 attributed to Patrícia Ferreira and PostDoctoral grant SFRH/BPD/101034/2014 attributed to Marlene Lopes, also under the scope of the projects RECI/BBB-EBI/0179/2012 (FCOMP-01-0124-FEDER-027462), the strategic funding of UID/BIO/04469/2013 unit and COMPETE 2020 (POCI-01-0145FEDER-006684).

\section{References}

[1] T.E. Arzumanov, N.V. Shishkanova, T.V. Finogenova, Biosynthesis of citric acid by Yarrowia lipolytica repeat-batch culture on ethanol, Appl. Microbiol. Biotechnol. 53 (2000) 525-529.

[2] A. Crolla, K.J. Kennedy, Fed-batch production of citric acid by Candida lipolytica grown on n-paraffins, J. Biotechnol. 110 (2004) 73-84.

[3] I.G. Morgunov, S.V. Kamzolova, O.A. Perevoznikova, N.V. Shishkanova, T.V. Finogenova, Pyruvic acid production by a thiamine auxotroph of Yarrowia lipolytica, Process Biochem. 39 (2004) 1469-1474.

[4] S.V. Kamzolova, J.N. Lunina, I.G. Morgunov, Biochemistry of citric acid production from rapeseed oil by Yarrowia lipolytica yeast, JAOCS, J. Am. Oil Chem. Soc. 88 (2011) 1965-1976.

[5] A. Beopoulos, J. Cescut, R. Haddouche, J.L. Uribelarrea, C. Molina-Jouve, J.M. Nicaud, Yarrowia lipolytica as a model for bio-oil production, Prog. Lipid Res. 48 (2009) 375-387

[6] C. Romero-Guido, I. Belo, T.M.N. Ta, L. Cao-Hoang, M. Alchihab, N. Gomes, et al., Biochemistry of lactone formation in yeast and fungi and its utilisation for the production of flavour and fragrance compounds, Appl. Microbiol. Biotechnol. 89 (2011) 535-547.

[7] P. Fickers, A. Marty, J.M. Nicaud, The lipases from Yarrowia lipolytica: genetics, production, regulation, biochemical characterization and biotechnological applications, Biotechnol. Adv. 29 (2011) 632-644. 
[8] C. Otto, M. Holz, G. Barth, Production of organic acids by Yarrowia lipolytica, in: G. Barth (Ed.), Yarrowia Lipolytica. Biotechnol. Appl., 25th ed., Springer Berlin Heidelberg, Berlin, Heidelberg, 2013, pp. 137-149.

[9] C. Gonçalves, M. Lopes, J.P. Ferreira, I. Belo, Biological treatment of olive mill wastewater by non-conventional yeasts, Bioresour. Technol. 100 (2009) 3759-3763.

[10] A. Chatzifragkou, S. Papanikolaou, Effect of impurities in biodiesel-derived waste glycerol on the performance and feasibility of biotechnological processes, Appl. Microbiol. Biotechnol. 95 (2012) 13-27.

[11] S. Karasu-Yalcin, Enhancing citric acid production of Yarrowia lipolytica by mutagenesis and using natural media containing carrot juice and celery byproducts, Food Sci. Biotechnol. 21 (2012) 867-874.

[12] G.S. Dhillon, S.K. Brar, M. Verma, R.D. Tyagi, Utilization of different agro-industrial wastes for sustainable bioproduction of citric acid by Aspergillus niger, Biochem. Eng. J. 54 (2011) 83-92.

[13] Y.D. Hang, E.E. Woodams, Production of citric acid from corncobs by Aspergillus niger, Bioresour. Technol. 65 (1998) 251-253.

[14] T. Roukas, Citric acid production from carob pod by solid-state fermentation, Enzyme Microb. Technol. 24 (1999) 54-59.

[15] Y.D. Hang, B.S. Luh, E.E. Woodams, Microbial production of citric acid by solid state fermentation of kiwifruit peel, J.Food Sci. 52 (1987) 226-227.

[16] D. Kumar, V.K. Jain, G. Shanker, A. Srivastava, Utilisation of fruits waste for citric acid production by solid state fermentation, Process Biochem. 38 (2003) $1725-1729$.

[17] A.M. Torrado, S. Cortés, J.M. Salgado, B. Max, N. Rodríguez, B.P. Bibbins, et al., Citric acid production from orange peel wastes by solid-state fermentation, Braz. J. Microbiol. 42 (2011) 394-409.

[18] A. Karthikeyan, N. Sivakumar, Citric acid production by Koji fermentation using banana peel as a novel substrate, Bioresour. Technol. 101 (2010) $5552-5556$.

[19] A. Angumeenal, D. Venkappayya, Artrocarpus heterophyllus-a potential substrate for citric acid biosynthesis using Aspergillus niger, LWT- Food Sci. Technol. 38 (2005) 89-93.

[20] M. Wojtatowicz, W. Rymowicz, H. Kautola, Comparison of different strains of the yeast Yarrowia lipolytica for citric acid production from glucose hydrol, Appl. Biochem. Biotechnol. 31 (1991) 165-174.

[21] S.B. Imandi, V.V.R. Bandaru, S.R. Somalanka, S.R. Bandaru, H.R. Garapati, Application of statistical experimental designs for the optimization of medium constituents for the production of citric acid from pineapple waste, Bioresour. Technol. 99 (2008) 4445-4450.

[22] S. Papanikolaou, M. Galiotou-Panayotou, S. Fakas, M. Komaitis, G. Aggelis, Citric acid production by Yarrowia lipolytica cultivated on olive-mill wastewater-based media, Bioresour. Technol. 99 (2008) 2419-2428.

[23] X. Liu, J. Lv, J. Xu, T. Zhang, Y. Deng, J. He, Citric acid production in Yarrowia lipolytica SWJ-1b yeast when grown on waste cooking oil, Appl. Biochem. Biotechnol. 175 (2014) 2347-2356.

[24] S. Papanikolaou, L. Muniglia, I. Chevalot, G. Aggelis, I. Marc, Yarrowia lipolytica as a potential producer of citric acid from raw glycerol, J. Appl. Microbiol. 92 (2002) 737-744.

[25] D.T. Johnson, K.A. Taconi, The glycerin glut: Options for the value-added conversion of crude glycerol resulting from biodiesel production, Environ. Prog. 26 (2007) 338-348.

[26] M. Metsoviti, S. Paramithiotis, E.H. Drosinos, M. Galiotou-Panayotou, G.J.E. Nychas, A.P. Zeng, et al., Screening of bacterial strains capable of converting biodiesel-derived raw glycerol into 1,3-propanediol, 2,3-butanediol and ethanol, Eng. Life Sci. 12 (2012) 57-68.

[27] G. Mothes, C. Schnorpfeil, J.U. Ackermann, Production of PHB from crude glycerol, Eng. Life Sci. 7 (2007) 475-479.

[28] L. Tomaszewska, A. Rywińska, W. Gladkowski, Production of erythritol and mannitol by Yarrowia lipolytica yeast in media containing glycerol, J. Ind. Microbiol. Biotechnol. 39 (2012) 1333-1343.

[29] W. Rymowicz, A.R. Fatykhova, S.V. Kamzolova, A. Rywińska, I.G. Morgunov, Citric acid production from glycerol-containing waste of biodiesel industry by Yarrowia lipolytica in batch repeated batch, and cell recycle regimes, Appl. Microbiol. Biotechnol. 87 (2010) 971-979.

[30] M. Lopes, N. Gomes, M. Mota, I. Belo, Yarrowia lipolytica growth under increased air pressure: influence on enzyme production, Appl. Biochem. Biotechnol. 159 (2009) 46-53.
[31] M. Lopes, N. Gomes, C. Gonçalves, M.A.Z. Coelho, M. Mota, I. Belo, Yarrowia lipolytica lipase production enhanced by increased air pressure, Lett. Appl. Microbiol. 46 (2008) 255-260.

[32] A. Braga, D.P. Mesquita, A.L. Amaral, E.C. Ferreira, I. Belo, Aroma production by Yarrowia lipolytica in airlift and stirred tank bioreactors: differences in yeast metabolism and morphology, Biochem. Eng. J. 93 (2015) 55-62.

[33] M. Workman, P. Holt, J. Thykaer, Comparing cellular performance of Yarrowia lipolytica during growth on glucose and glycerol in submerged cultivations, AMB Express 3 (2013) 1-9.

[34] H. Okoshi, S. Sato, S. Mukataka, J. Takahashi, Citric acid production by Candida tropicalis under high dissolved oxygen concentrations, Agric. Biol. Chem. 51 (1987) 257-258.

[35] T.V. Finogenova, N.V. Shishkanova, E.A. Fausek, S.S. Eremina, Biosynthesis of isocitric acid from ethanol by yeasts, Appl. Microbiol. Biotechnol. 36 (1991) 231-235.

[36] A. Rywińska, I. Musiał, W. Rymowicz, B. Żarowska, T. Boruczkowski, Effect of agitation and aeration on the citric acid production by Yarrowia lipolytica grown on glycerol, Prep. Biochem. Biotechnol. 42 (2012) 279-291.

[37] S.V. Kamzolova, E.G. Dedyukhina, V.A. Samoilenko, J.N. Lunina, I.F. Puntus, R.L. Allayarov, et al., Isocitric acid production from rapeseed oil by Yarrowia lipolytica yeast, Appl. Microbiol. Biotechnol. 97 (2013) 9133-9144.

[38] F. Garcia-Ochoa, E. Gomez, Bioreactor scale-up and oxygen transfer rate in microbial processes: an overview, Biotechnol. Adv. 27 (2009) 153-176.

[39] S. Suresh, V.C. Srivastava, I.M. Mishra, Techniques for oxygen transfer measurement in bioreactors: a review, J. Chem. Technol. Biotechnol. 84 (2009) 1091-1103.

[40] C.M. Cooper, G.A. Fernstrom, S.A. Miller, Performance of agitated gas-liquid contactors, Ind. Eng. Chem. 36 (1944) 504-509.

[41] N.P. Cheremisinoff, R. Gupta, Handbook of Fluids in Motion, Butterworth Publishers, Woburn, MA, USA, 1983.

[42] W.S. Wise, The measurement of the aeration of culture media, J. Gen. Microbiol. 5 (1951) 167-177.

[43] P.F. Stanbury, A. Whitaker, Principles of Fermentation Technology, Pergamon Press, Oxford [Oxfordshire], 1984.

[44] L.S. Tribe, C.L. Briens, A. Margaritis, Determination of the volumetric mass transfer coefficient $\left(k_{\mathrm{L}} a\right)$ using the dynamic gas out-gas in method: analysis of errors caused by dissolved oxygen probes, Biotechnol. Bioeng. 46 (1995) 388-392.

[45] B. Bandyopadhay, A.E. Humphrey, H. Taguchi, Dynamic measurement of the volumetric oxygen transfer coefficient in fermentation systems, Biotechnol. Bioeng. 4 (1967) 533-544.

[46] B.J. Michel, S.A. Miller, Power requirements of gas-liquid agitated systems, AIChE J. 8 (1962) 262-266

[47] Y. Kawase, M. Moo-Young, Volumetric mass transfer coefficients in aerated stirred tank reactors with newtonian and non-newtonian media, Chem. Eng. Res. Des. 66 (1988) 284-288.

[48] P.F.F. Amaral, M.G. Freire, M.H.M. Rocha-Leão, I.M. Marrucho, J.A.P. Coutinho, M.A.Z. Coelho, Optimization of oxygen mass transfer in a multiphase bioreactor with perfluorodecalin as a second liquid phase, Biotechnol. Bioeng. 99 (2008) 588-598.

[49] C.S. Shin, M.S. Hong, J. Lee, Oxygen transfer correlation in high cell density culture of recombinat E. coli, Biotechnol. Tech. 10 (1996) 679-682.

[50] K.D. Rane, K.A. Sims, Oxygen uptake and citric acid production by Candida lipolytica Y 1095, Biotechnol. Bioeng. 43 (1994) 131-137.

[51] S.D. Wentworth, D.G. Cooper, Self-cycling fermentation of a citric acid producing strain of Candida lipolytica, J. Ferment. Bioeng. 81 (1996) 400-405.

[52] T.V. Finogenova, S.V. Kamzolova, E.G. Dedyukhina, N.V. Shishkanova, A.P. Il'chenko, I.G. Morgunov, et al., Biosynthesis of citric and isocitric acids from ethanol by mutant Yarrowia lipolytica N 1 under continuous cultivation, Appl. Microbiol. Biotechnol. 59 (2002) 493-500.

[53] S.V. Kamzolova, N.V. Shishkanova, I.G. Morguniv, T.V. Finogenova, Oxygen requirements for growth and citric acid production of Yarrowia lipolytica, FEMS Yeast Res. 3 (2003) 217-222.

[54] S. Anastassiadis, H.J. Rehm, Citric acid production from glucose by yeast Candida oleophila ATCC 20177 under batch, continuous and repeated batch cultivation, Electron. J. Biotechnol. 9 (2006) 26-39. 